\title{
Alessandro Giarda, Esperienze della sovranità. Il surrealismo di Georges Bataille e Antonin Artaud
}

\section{Marcella Biserni}

\section{(2) OpenEdition}

1 Journals

\section{Edizione digitale}

URL: http://journals.openedition.org/studifrancesi/7695

DOI: 10.4000/studifrancesi.7695

ISSN: 2421-5856

\section{Editore}

Rosenberg \& Sellier

\section{Edizione cartacea}

Data di pubblicazione: 1 décembre 2009

Paginazione: 663-664

ISSN: 0039-2944

\section{Notizia bibliografica digitale}

Marcella Biserni, «Alessandro Giarda, Esperienze della sovranità. I/ surrealismo di Georges Bataille e

Antonin Artaud», Studi Francesi [Online], 159 (LIII | III) | 2009, online dal 30 novembre 2015, consultato il 09 janvier 2021. URL: http://journals.openedition.org/studifrancesi/7695 ; DOI: https://doi.org/

10.4000/studifrancesi.7695

Questo documento è stato generato automaticamente il 9 janvier 2021.

\section{(c) (1)}

Studi Francesi è distribuita con Licenza Creative Commons Attribuzione - Non commerciale - Non opere derivate 4.0 Internazionale. 


\title{
Alessandro Giarda, Esperienze della sovranità. Il surrealismo di Georges Bataille e Antonin Artaud
}

\author{
Marcella Biserni
}

\section{NOTIZIA}

ALESSANDRO GIARDA, Esperienze della sovranità. Il surrealismo di Georges Bataille e Antonin Artaud, a cura di Diego SCARCA, Vercelli, Edizioni Mercurio, 2008, pp. 205.

1 I termini sovranità e surrealtà, già nel titolo, costituiscono la filigrana che lega il contenuto del testo e il perno attorno al quale ruota il gioco di rimandi tra Ba-taille, Artaud e il surrealismo di Breton. I tre capitoli di A. Giarda che compongono il volume sono chiusi ciascuno da pagine di Diego Scarca, curatore dell'intero lavoro.

Le riflessioni poggiano sul concetto di sovranità come moto perpetuo che dà vita, distrugge e trasforma, idea che si concilia con il surrealismo, ma che in Bataille e Artaud assume accezioni e percorre strade diverse, pur partendo da elementi comuni: la poesia, l'amore, la libertà. Alessandro Giarda e Diego Scarca si propongono di esplicitare queste esperienze di sovranità prendendo in considerazione, nel primo capitolo, i concetti studiati da Ba-taille fin dagli anni Trenta: la nozione di dépense e la dualità inconciliabile tra sacro e profano. Si tratta di una rilettura del suo pensiero filosofico, filtrato da Hegel e da Nietzsche, che sfocia nel concetto di "festa" in un'ottica di rovesciamento carnevalesco complementare al sacrificio e all'atto liberatorio, unica possibilità per recuperare la soggettività umana al di là dell'utile e accedere, così, alla sovranità.

Questi punti cardine fungono da trait-d'union con il pensiero di Artaud che i due autori, nel secondo capitolo, riescono a conciliare con quello di Ba-taille, mettendone in evidenza le diversità nella teorizzazione, ma non nel risultato finale. In un primo momento, al centro del dramma artaudiano, spiegato attraverso varie citazioni tratte 
da Guattari e Deleuze, viene analizzata la questione dell'incomunicabilità come esigenza mancata, che colpisce sia l'anima che il corpo. Nella seconda parte, si sottolinea la sintonia di questo sentire con la definizione di "sovranità" data da Bataille, come scivolamento verso il "niente", termine che «serve a designare ciò che il pensiero oggettivo non riesce a comprendere e afferrare saldamente» (p. 121).

Questi due pensieri, uno filosofico l'altro poetico, rivolti a un tipo di energia senza riserve e a un consumo finalizzato solo alla trasgressione, rimandano inevitabilmente al surrealismo. Ecco che l'ultimo capitolo cerca di evidenziare, partendo da questo snodo, l'evoluzione di Ba-taille e Artaud mettendola a confronto con la visione rivoluzionaria di Breton. L'amore, la poesia e l'humour surrealisti vengono sviscerati dagli autori e rivisitati dallo sguardo dei due critici del Surrealismo, per i quali la sovranità è un'anarchia che si organizza e che sfugge al giudizio. Dunque, regna sovrano il rigore insito nel teatro della crudeltà che espelle il male e libera l'uomo attraverso l'atto alchemico, che è assente nell'esperienza surrealista. Qui, tutto è lasciato automaticamente allo hasard objectif e la surrealtà di Breton rimane un'azione sospesa, che è solo un'approssimazione della sovranità. L'epilogo mostra quanto le due utopie divergano: l'una resta un ideale e l'altra è ricondotta all'immanenza per sfruttare qualsiasi innesco della sovranità (la poesia autentica, il teatro crudele, l'amore al di là dell'erotismo). Per «riconciliare ogni uomo, momentaneamente o no, con la vita» (p. 173). 